\title{
Alice in Wonderland Syndrome: The First Case of Arbitrary, Reproducible, Early Childhood AIWS-like Visual Sensations in a Meditation Setting
}

\author{
Bittmann S*, Moschüring-Alieva E, Luchter E, Weissenstein A, Bittmann L and Villalon G \\ Department of Pediatrics, Ped Mind Institute, Germany
}

*Corresponding author: Stefan Bittmann, Department of Pediatrics, Ped Mind Institute (PMI), Germany

To Cite This Article: Bittmann S, Moschüring-Alieva E, Luchter E, Weissenstein A, Bittmann L, Villalon G. Alice in Wonderland Syndrome: The First Case of Arbitrary, Reproducible, Early Childhood Aiws-like Visual Sensations in a Meditation Setting. 2020 - 9(3). AJBSR.MS.ID.001395. DOI: 10.34297/AJBSR.2020.09.001395.

Received: 眥: June 08, 2020; Published: 監 July 01, 2020

Keywords: Alice in Wonderland syndrome-physical abuse-arbitrarily induced

\section{Introduction}

Alice in the wonderland syndrome (AIWS) was named after the description by Lewis Carroll in his novel. It was in 1955 when John Todd, a psychiatrist, this entity described for the first time. Todd described it as "Alice's Adventures in Wonderland" of Lewis Carroll. The author Carroll suffered from heavy migraine attacks. The Alicein-Wonderland-Syndrome is a bewildering state of attacks which affect the visual perception. AIWS is a neurological form of attacks which concern the brain and cause a perception disturbance. The patients describe visual, auditive and tactile hallucinations and perception disturbances. The causes of the AIWS are not exactly known yet. Cases of migraine, brain tumours, depression episodes, epilepsy, delirium, psychiatric drugs, ischemic stroke, EBV, mycoplasma infection and malarial infections correlate with attacks of AIWS. Neuroimaging studies show disturbances of brain regions including the temporoparietal junction, of the temporal region and the occipital region as a typical localisation of the visual road.

\section{Next chapter/title}

Age-Related Chronological Personal Retrospective Description (67 y old Californian, USA, e-mail interview setting).

The individual chronological report was described by a 67-yearold man who contacted me from California, USA, in early June 2020. An e-mail interview was analyzed and described afterwards as follows:
Fever before the age of 9. The people who talked to me sounded as if they were talking very fast. I felt like I was standing on my head. I was with my grandmother and on her red sofa. I found out later that I was not there, but in my own house.

Age 9, evening watching TV lying down. The visual perception was like looking through the wrong end of binoculars. Everything was pushed far away. lasted only a short time.

Age 15, during the night drive. The same visual perception as at age 9 had to be run over because of the distortion, Lasted a few minutes.

Age 21, Out during daytime meditation. As I relaxed more, the visual perception as at the age of 9 happened spontaneously. Even though my eyes were closed, I knew that if I opened my eyes I would see through the wrong end of binoculars. Then the physical sensations began. I sat outside with my legs crossed, but I could not feel my body. It was as if I had no body and although I was outside and the sun was shining I was in complete darkness. I didn't know where or how my body was positioned. It was like I was in space and I was a point of energy. I felt calm and peaceful. There was a feeling that I could go deeper into the stillness, but I hesitated. I got a little frightened because I had the feeling that I could stay there forever and could not come out again. (Now if you actually look through the wrong end of a pair of binoculars, it is only a visual thing, you don't feel anything. But in the AIWS I felt a feeling in my eyes. I might 
feel like a pull on my temples). When I hesitated and decided to get out of my meditation I opened my eyes, but the visual perception continued. Everything was still far away. I shook my head and in a few seconds I was back to normal.

Age Early 30. After meditating back and forth for years, I could not meditate deeply, as the yogis said. It was always what I call superficial meditation. I wanted to get the feeling of going into deep meditation, and I thought if I could get this thing going with visual perception, so I focused on my pineal gland and my eyes to see if I could deliberately evoke the visual perception, and I did it inside of me for a few minutes. What I found out was that I could only go as deep into meditation as I did at 21 because the old fear would return. Get stuck there. In the following years I tried to break through this barrier of fear, but I couldn't. What happened was that it was more difficult to become normal again. It took longer for the wrong end of binocular vision to return to normal. I don't see them as seizures. But nothing unusual happens before the early effects. Nothing unusual before the ones I initiated. Towards the end of my AIWS experience, I did not mention that I met a man who could address AIWS at will even during mediation. We did this once at the same time in the same room where we were facing each other and were able to connect with each other within the experience. We could see the same thing and verbally describe what we saw to each other. It was really a crazy thing. But it really happened. It only lasted a short time. For some reason we were pushed away from the experience. Speaking of which. Speaking in AIWS at the same time was a little difficult. It was slow and measured. That's what I said, and also why I don't see AIWS as a seizure. I intentionally induced the experience through meditation between my late 20s and early 40s. Then I lost the ability to do it and I didn't have a spontaneous episode.

\section{Parents}

The father was ill-treated verbally and physically. He would hit us because of unimportant things. E.G., he did not wipe up the ground. Mother was passive. She could not stop the maltreatment. Physically. Whip with different kinds of objects. Belt, a pliable hard rubber belt which he produced, tree branches. (Of the counters). This is primarily the reason, why I left over and over again from home. Now which began maltreatments when we were still very young, I believe, I was 5 years old. It could have been former, but I cannot remember any more. And stopped for me when I left with 17 from home. There could be a connection. I have a brother and three sisters, and nobody has made my experience. Till the last week I did not know the reason for it. Possible reason. From my aunt, the sister of my mother, I found out that my mother wanted to do no house works in the house. She always had an excuse. She had of rheumatic table fever and a heart noise when it was young. Everybody looked after them. The poor baby. After she was better, it was as expected that people looked after them. However, my father came from a clean home. At that time one expected that the woman is clean and holds ready food if my father comes home. This never was the case. She always had an excuse. To look after the babies. I believe, my father took amiss me of this and let out it on me and the other. They have other problems. All basic, textbook-like problems. I have run away with 15-16 from home. With 17 I have saved money and have run away about a 1 year from home. Then suddenly, in the end of 30 , in the beginning of 40 , I could not return any more intentionally by meditation in this space. I was made easier anyhow, but was also disappointed. I still meditate and can be relaxed very much, but I could still feel my body. During and after the AIWS episodes other things have happened, but they are much stranger and less plausible than the AIWS.

\section{Discussion}

In 1955 the British psychiatrist John Todd (1914-1987) described the state micro - and macrosomatognosia, the changed perception of the body image and body images, and called it the Alice in Wonderland Syndrome. In 1955 John Todd has described syndrome and has given it a literary name in its publication. The first description of the syndrome comes from Lippman et al. 1952. Alice in Wonderland Syndrome includes false perceptions of the body image, the shape of objects, the sense of time and illusionary visual perceptions. Body perception deprivation of illusionary and fear, sometimes for many years in early childhood, and can affect the child's normal development in the family and environment [1]. AIWS has been described in various publications in relation to many different infectious diseases such as marsh fever, zicavirus, varicella-induced optic neuromyelitis, Lyme disease, H1N1 influenza infection and mononucleosis. It is obvious that all these different diseases play no role in the search for the true origin of Alice in Wonderland Syndrome. Other entities like complicated partial epilepsy, migraines, acute have spread encephalomyelitis, drug abuse like LSD or montelukast (mast cell equalizer) is other related drug correlations in connection with AIWS-like seizures. Furthermore, recent articles describe AIWS seizures thereafter ventriculoatrial shunting surgery in hydrocephalus post-operative and in patients with brain tumor, especially glioblastoma. Recent publications describe the curious aspect of AIWS seizures, which constantly correspond to physical abuse [2-4]. In these publications, two older women, aged 57 and 61, describe their terrible experiences of sexual abuse and have continuously correlated AIWS attacks after many years [2,3,5]. These case studies shed light on aspects of physical and sexual abuse by describing the entity that appeared many years after this unfamiliar experience of two older women analyzing their experiences as children [3]. These reasonable and strange descriptions and beautiful descriptions of two older women from the United States and the United Kingdom should be supported by further cases and research. The subject is very sensitive, very curious and should be analysed with other cases [6,7]. In our chronological individual case report, a 67-yearold man describes in detail his childhood experience before the age 
of 9 with vision problems in the form of AIWS vision impairment and physical abuse of the father. The patient described these experiences together in the correlation. Finally, this report has shed light on another case of physical abuse and AIWS-like vision disorders. Surprisingly, AIWS sensations could be arbitrarily induced by himself later, especially between the ages of 20 to 40 through meditation. After this age of 40 the visual experience and AIWS like sensations have been finished and were not described further in this patient. The Californian patient never were ill before, nor took any medications or drugs. Important in this patient is the arbitrary initiation of AIWS like sensations and is therefore the first case in world literature and to date, never has been found this entitiy or has been published. Fact is, AIWS like visual sensations are reproducible in a concentrated meditation setting.

\section{Reference}

1. Cohen MN (1996) Lewis carroll. A biography. Vintage Books, New York, USA.
2. Bittmann S (2018) The clue to the unknown origin of Alice in Wonderland in Children? Pediatr Res Child Health 1: 001.

3. Bittmann S, Luchter E, Villalon G (2018) Does sexual abuse play a causative role in Alice in Wonderland Syndrome in Childhood? A help screaming from internet. J Perina Clin Pediatr 104.

4. Bittmann S (2018) Abuse in children: Indicator of failure in relationship? Adv Pediatr Res 5:16.

5. Bittmann S Alice in Wonderland Syndrome in childhood: Abuse is the root? J Pediatr Dis 2.

6. Bittmann S, Weissenstin A, Luchter E, Alieva EM, Villalon (2019) First Case of Alice in Wonderland-like Seizures in a Mother and her Daughter: A New Sign for a Hereditary Origin? Am J Biomed Sci \& Res 6(4): 301303.

7. Weissenstein A, Luchter E, Bittmann S (2014) Alice in Wonderland syndrome: A rare neurological manifestation with microscopy in a 6year-old child. J Pediatr Neurosci 9(3): 303-304. 